Nr 229 • 1994

Systematic Cooperation between Driving Schools and Parents in Driver Education, an Experiment

Nils Petter Gregersen

Reprint from Accident Analysis \& Prevention, Vol. 26, No. 4, 1994, pp. 453-461

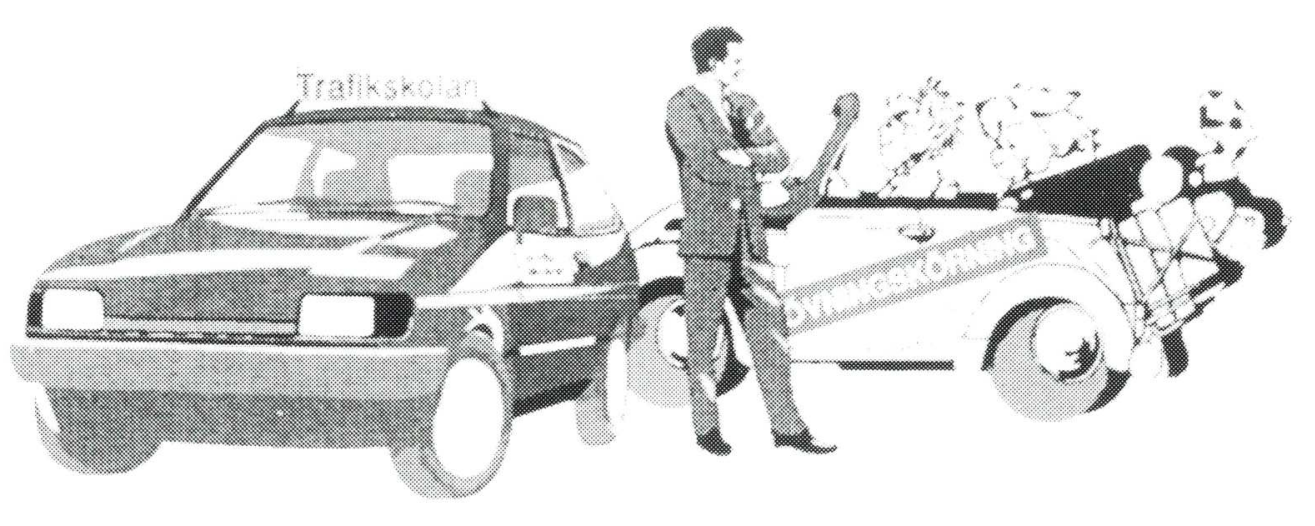

d

- Väg-och transport- 



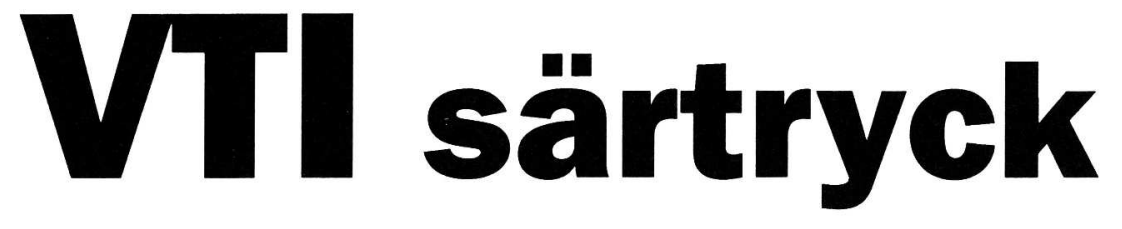

Nr $229 \bullet 1994$

Systematic Cooperation between Driving Schools and Parents in Driver Education, an Experiment

\section{Nils Petter Gregersen}

Reprint from Accident Analysis \& Prevention, Vol. 26, No. 4, 1994, pp. 453-461 


\title{
SYSTEMATIC COOPERATION BETWEEN DRIVING SCHOOLS AND PARENTS IN DRIVER EDUCATION, AN EXPERIMENT
}

\author{
Nils Petter Gregersen
}

\begin{abstract}
Swedish Road and Transport Research Institute (VTI), S-581 01 Linköping, Sweden, and Dept. of Community Medicine, University of Linköping, Linköping, Sweden
\end{abstract}

(Accepted 6 September 1993)

\begin{abstract}
The overall purpose of the experiment is to study the effects of various educational changes as a measure for preventing accidents among young drivers. The hypothesis is that accident risks among young drivers, normally educated by private instructors, i.e. parents, will be reduced if complementary professional education and support are provided. To analyze the effect of this combination of private and complementary professional driver education compared to solely private instruction, nearly 2,000 young people, 17 years old, were divided into two groups. The experimental group was given professionally supported education and the control group was educated by parents or other private teachers. The changes comprised three parts, systematic cooperation between driving school and parents, "commentary driving" to improve scanning behaviour, and special practice to help the learner experience his own limitations in driving skill. The results based on self-reported accident show negative effects during the first year and positive effects of the changes during the second year after licensing. When the two years were added, no significant change was found. Questionnaire data in subjective skill and driving style showed small changes, the experimental group being a little more careful and a little less self-confident. The results are discussed in terms of cognitive overload and the learners' limited capacity to benefit from the changes during the first of the two years.
\end{abstract}

Keywords-Driver training, Recently qualified driver, Safety, Driving instructor

\section{INTRODUCTION}

It is a well-known fact that young drivers are involved in considerably more accidents than older, more experienced drivers. The latest figures from Sweden show an overrisk of $700 \%$ among drivers aged 18-19 (Spolander 1992). In 1984, a special Swedish group made an analysis of young drivers' problems and also suggested various countermeasures in terms of driver training and education.

The present study was designed on the basis of this analysis of young drivers' problems. Three basic and important problems were pointed out (Spolander et al., 1984):

1. Private driver education is not sufficiently governed by rules and curricula. In Sweden, it is possible to obtain driver education either in professional driving schools or privately with a nonprofessional instructor. The professional schools apply rules and a curriculum, but learners who do not make use of the professional driving schools lack the necessary structure. A high proportion of drivers $(21 \%)$ obtain their education with private, unprofessional teachers, which is considered to result in poorer drivers, since these teachers are not acquainted with deciding what is important to teach and how to teach it. In addition, $51 \%$ combine private learning with one or more lectures at the traffic school. With the proper guidance from professional driving schools, private training may be regarded as an important means of gaining more practice and experience.

2. Young drivers' perceptional behaviour has severe limitations. They do not make use of their peripheral vision. They focus on the road, close to the front of the car, etc. Consequently, they fail to discover obstacles and critical situations on the road (Mourant and Rockwell 1972), which may lead to increased involvement in accidents. Their reaction time in traffic situations is also prolonged 
when they become drivers. These are certainly not physiological changes, but a problem of cognitive capacity. A novice driver has to deal consciously with so many things that his cognitive capacity is insufficient.

3. Young drivers tend to overestimate their own capacity as car drivers. It has been shown in several studies that young male drivers, especially, believe they are better than the average driver. If a driver believes that he is skilled, this leads to lower risk evaluation and more risk taking. Young drivers do drive faster than older drivers, they keep shorter distances, they have more violations etc. (Evans, Wasielewsky, and Von Buseck 1982; Evans and Wasielewsky 1983; Finn and Bragg 1986).

The group concluded its work by suggesting an experiment in which three measures could be tried out in driver education, each of them with the aim of reducing one of the three problems:

1. The solution to the problem of private teaching was not to forbid this part of the teaching. but to give the private teachers guidance and help. Private teaching was regarded as a resource for gaining experience and routine. while professional teachers should be responsible for teaching new knowledge and skills and for structuring private instruction.

2. It was suggested that the perceptional problems should be reduced by using the method of "commentary driving" to improve drivers' scanning behaviour and risk evaluation. It is based on a strategy that the learner. during driving, reports to the teacher on what is happening around him. Through feedback from the teacher, this scanning skill is expected to be improved.

3. To reduce overestimation, it was suggested that the drivers should be put in situations in which they should not practice driving skill, but rather experience their own limitations better. Practical training could be developed with the purpose of surprising the learners and making them fail in driving tasks that they normally believe they can handle.

\section{AIMS}

Following the suggestions in the report referred to above, the aim of this study has been to analyse the preventive effects of the combination of these three changes upon accident risk. This means struc-

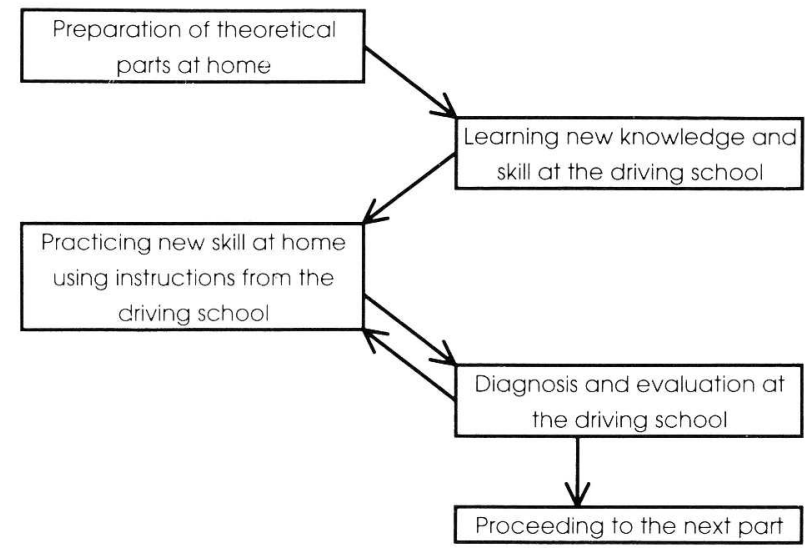

Fig. 1. Model for the integration of professional and private driver education.

tured support by the driving school, use of "commentary driving," and special insight-creation training. The hypothesis that the accident risk will be reduced during the first two years with a licence is tested. An experiment was designed with the new model for drivers' education instead of the free model of private education.

\section{METHODS AND MATERIAL}

\section{Description of experimental driver training}

To reduce the problems described above, three measures were tested in the experiment (for further details, see Gregersen 1992a). The problems of private teaching were tackled by giving the privately taught drivers theory lessons in accordance with the Swedish official curriculum together with 16 lessons, each lasting an average of 45 minutes, in practical driving at a professional driving school. This professional part was combined with training at home as described in Fig. 1.

The participation of the private teacher in an introduction and four of the driving lessons was also mandatory. As guidance for the private training, twelve new instruction folders were designed and distributed successively during the learning period. These folders contained verbal and graphic instructions for the private teacher and for the learner driver.

The second measure, to improve perception and scanning behaviour, was method of "commentary driving" in the driving schools (Marek and Sten 1977). The idea of the method is that the learner should give oral reports, telling the teacher what is happening while driving, The ability to give these verbal reports is developed in four steps: 
1. Reporting actions (i.e. "shifting gear, looking in the mirror, pressing the brake pedal,", etc.)

2. Reporting observations (i.e. "a child on the sidewalk, a line of parked cars, a stop sign,", etc.).

3. Reporting risks (i.e. "the child might jump out into the street without looking, someone might open a car door," etc.).

4. Reporting preventive measures (i.e. "be prepared and watch the child, keep a proper distance to the line of parked cars," etc.).

The method was used for 5-10 minutes during each driving lesson. The idea was to improve the learner's ability to see what was happening around him. The learner's perception, evaluation of risks, and ideas for preventive measures are also reflected, thus enabling the teacher to give immediate feedback.

The third measure, reducing the learner's overestimation, introduced a series of training tasks that allowed the learner to experience his own limitations.

These tasks were based upon various potentially dangerous situations such as maneuvering on icy roads, driving in darkness, and driving in areas with wildlife. One of the tasks, driving in darkness, will be described as an example (Fig. 2).

A teacher is sitting in a parked car, and the learner and another instructor are driving in another car. The instruction is to practice shifting from high to low beam. The task is performed when passing the parked car. The learner drives along a road which leads back to where he started, and the instruction is repeated. This time, however, a dummy (a cylindrical object of soft, black-colored material) is placed in the way of the learner's car. He discovers it too late and runs into it. The teacher promptly starts a discussion about the problem and helps the learner to draw the right conclusions about his own skill and limitations.

Similar tasks were developed to improve experience of several potentially dangerous situations.

These three measures, in combination with the normal curriculum of professional driver education, formed the change in the experimental group. The educational approach and content were developed in close cooperation with the driving school organization and the authorities to maximize feasibility in practice.

\section{Evaluation method}

The design of the study is experimental. The samples were drawn in two steps. In the first, 12,000 persons aged 17 were randomly drawn from the Swedish population and address register (SPAR).

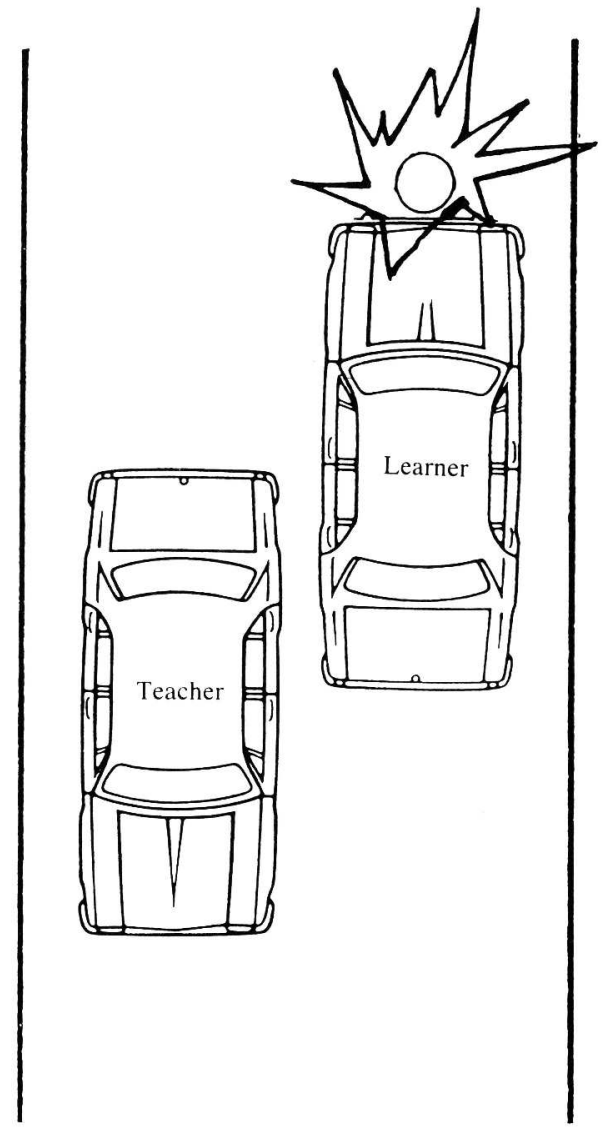

Fig. 2. Illustration of practice in darkness.

They received a short questionnaire about their plans for obtaining a drivers' licence, i.e. whether they planned to join a driving school or learn from a private teacher. The Swedish system allows people to make their own choice. The eye of the needle that everyone has to pass through is the finishing theoretical and practical driving test.

From this questionnaire, 1,894 persons were found who planned to learn from private teachers. These were distributed into two groups, one experimental group and one control group. The division could not be made strictly on a random basis since the experimental group was to attend driving schools, and it was necessary to reduce the geographical distance to the schools as much as possible. In certain small villages, all of those within the sample were picked for the experimental group. To balance this, a similar village was chosen for the control group. In cities with many young people from the sample, every second person was distributed to the experimental and control groups, respectively.

The control group consisted of 947 persons. The same number, 947 persons, in the experimental group was invited to take part in education at a driving school, almost free of charge. Only about 
$5 \%$ of the normal cost had to be paid, just to give them a feeling of making at least some investment.

There were 65 participating driving schools. They were chosen among schools that had shown interest in participating when asked.

Ninety-one percent of the experimental group accepted the offer and signed a "contract" describing what was expected from them. Eighty-one persons did not accept; thus the experimental group now consisted of 866 persons. During their education, 20 learners broke the contract, so the effective sample size of the experimental group was 846 .

Data were collected in different ways. The most important sources were three questionnaires sent to the young drivers, directly after licensing, and one year and two years after licensing. The first included process-evaluation questions about the learning period, amount of practice, formative evaluation of the education, etc. In the two following questionnaires, the drivers reported how much they had been driving and their number of accidents. (Accidents were defined in the questionnaire to include damage to the car and injury to anyone involved in the accident.) The drivers also estimated their driving skill and described their driving style in five-step scales. The two last questionnaires were similar.

The data collection also included a processevaluation questionnaire to the private teachers directly after licensing and interviews with the professional teachers involved in the experiment.

In total, six questionnaires were distributed to the learners, three to each of the two learner groups and one to the private teachers of the experimental group. The response rates for these questionnaires ranged from $85 \%$ to $90 \%$. There was no systematic difference between the two groups in terms of response rate. No nonresponse analysis was made.

\section{Statistics}

The effects upon accident risk were analysed from the number of accidents in relation to mileage. The hypothesis was tested with $95 \%$ confidence intervals for the risk quota of the two groups, based on the formula:

$$
\frac{\lambda_{1} / \lambda_{2}}{1+K \cdot S D}<\frac{\lambda_{1}}{\lambda_{2}}<\frac{\lambda_{1} / \lambda_{2}}{1-K \cdot S D} .
$$

If the confidence interval includes 1.0 , the hypothesis is rejected in a two-tailed test. In a one-tailed test, the hypothesis of a higher risk in the experimental group is rejected if the confidence interval includes 1.0 or is entirely above $1.0 . K$ is 1.96 for a confidence interval of $95 \%$ in two-tailed tests and
1.645 in one-tailed tests. $\lambda_{1} / \lambda_{2}$ is the accident risk quota in the sample (Spolander 1983).

Other comparisons are made with chi-square tests and $t$-tests. The level of significance was set to $5 \%$.

\section{RESULTS}

The experimental and control groups reported a similar amount of private practice, on an average 45 hours in the experimental group and 42 hours in the control group. The experimental group had, as expected, an average of 16.5 driving lessons (11.5 hours). Many of the learners took extra driving lessons, which they paid for themselves. In the control group, some of the learners also decided to go to driving schools. However, the average amount of driving tuition was as low as 2.6 hours.

The main results are found in the differences in accident risk. During the first year, the experimental group had a higher risk, 0.44 accidents $/ 10000 \mathrm{~km}$ compared to 0.30 in the control group. During the second year, the risk in the control group was higher, 0.24 , than in the experimental group, where the risk was 0.17 . When the two years were added, no significant difference was found (Fig. 3). The confidence intervals are given in Table 1.

The hypothesis stated that a reduction was expected in the experimental group compared to the control group. During the first year, this hypothesis was rejected. Since the results so clearly show the reverse distribution of the risk, the differences were tested with a two-tailed test. This test shows that the difference is significant.

From the self-assessment of driving skill, a consistent pattern for most of the nine different types of skill was found. In most cases, there was a small but significant difference-the control group was subjectively more skilled than the experimental group (Fig. 4).

The same kind of questions were also asked after two years of driving. No differences were found at this time. As a measure of driving style, some questions were asked about their driving speeds on rural and urban roads compared to other car drivers. The distribution over the two years is similar, but significant only during the second year-the control group members drove a little faster (Fig. 5).

From the process evaluation in the experimental group, it was shown that the majority of the learners as well as the teachers, were satisfied with the new education. In the interviews with the participating professional teachers, $95 \%$ were generally speaking positive to the changes, even if many of them criticized minor points regarding the instruc- 


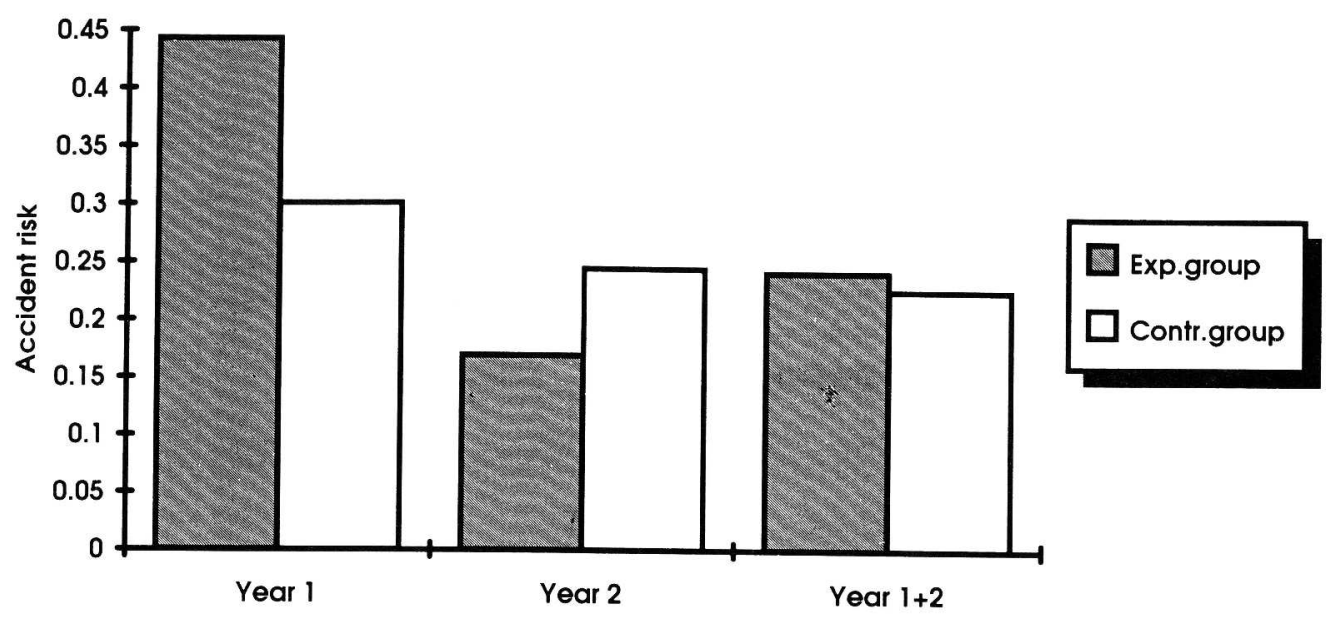

Fig. 3. Accident risk in the experimental and control groups, one year and two years after licensing.

tions for private teaching, the number of lessons, the distribution of time, etc. Approximately two thirds of the instructors would prefer to continue with this integrated teaching model. The main problem from the teachers' point of view was that the learners did not practice sufficiently at home.

Private instructors and learners in the experimental group were also decidedly positive in most respects. According to their ratings in the questionnaires, $80 \%-90 \%$ were positive to the cooperation with traffic schools, to the different features of the training, to the idea of using special instruction folders for the private training, etc.

There were, however, some problems. The questionnaire data show that the experimental group felt that they received low priority in the driving schools compared to other, "normal" learners. It was also reported that not all the professional teachers followed the instructions for the experiment. One example of this is demonstrated by the distribution of the 12 instruction folders. Instead of giving them to the learner one by one, following the curriculum, some teachers used other methods. In a few cases, all 12 were given out together.

\section{DISCUSSION}

\section{Discussion of the methods}

The experiment included rather large groups of learners and has been carried out as a field experi-

Table 1. Confidence intervals (95\%) of the risk quota of the experimental and control groups, one and two years after licensing. Two-tailed test $\mathrm{H}_{0}:$ Risk $_{\text {exp }}=$ Risk $_{\text {contr }}$

\begin{tabular}{lccc}
\hline & $\begin{array}{c}\text { Lower } \\
\text { conf. limit }\end{array}$ & $\begin{array}{c}\text { Risk quota } \\
\text { in sample }\end{array}$ & $\begin{array}{c}\text { Upper } \\
\text { conf. limit }\end{array}$ \\
\hline Exp/Contr. year 1 & 1.2723 & 1.4721 & 1.7463 \\
Exp/Contr. year 2 & 0.5644 & 0.6932 & 0.8980 \\
Exp/Contr. year 1 +2 & 0.9473 & 1.0697 & 1.2285 \\
\hline
\end{tabular}

ment. This means advantages as well as problems, both methodologically and concerning conclusions that can be drawn.

The purpose of the study was to try a new model of education in the field within the normal organization of traffic schools in Sweden. This offers possibilities for learning how schools, teachers, and learners make use of the ideas, as well as the effects on accident risk. These two aspects together form the basis for conclusions when it comes to making general use of the changes.

The advantage of a high level of reality is, however, combined with a loss of control over the details of what is really happening during the experiment. To have this control it is necessary to add to the evaluation of the effects a deeper process evaluation, where the process is studied in the schools and inside the cars, determining how cooperation works, analyzing practical problems, etc. Since this is a time-consuming and costly task, the process evaluation in this project has been limited to the one-time questionnaires and interviews with learners and teachers.

The follow-up process also included spontaneous contacts with schools or learners when problems were reported to the research staff. The number of such contacts was large.

During the analysis of what happened during the education process, a number of problems were identified from the questionnaire and interview data regarding conformance by learners and teachers with their instructions. These problems were not the only ones. Other problems were reported through spontaneous phone calls and letters from teachers and learners. One such interesting problem was that there were difficulties in defining the tasks and the responsibilities of the two different categories of teachers. Many reports indicated that the private 


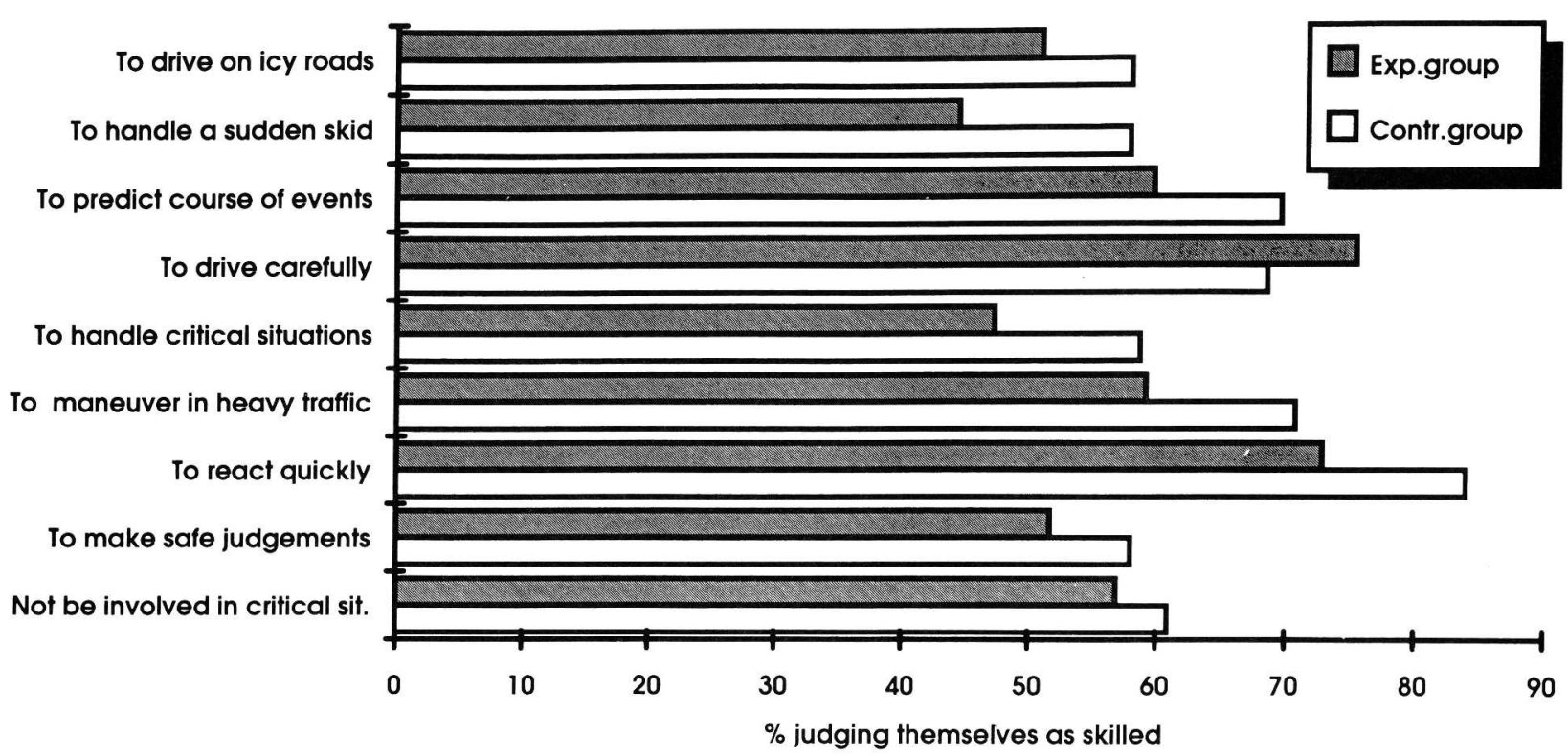

Fig. 4. Self-assessment of driving skill directly after licensing. Assessment made on a scale of 1-5.

teacher shifts the responsibility on to the professional teacher and vice versa. This may lead to reduced commitment, which was certainly not the intention. The idea was that the responsibility should be shared between both teacher categories. This may also explain why many of the professional teachers reported that the learners did not practice enough at home.

The conclusion can be drawn that there have been problems of a normal nature for this kind of field experiment, where there is no possibility of controling every factor. However, the majority of the participants in the project did a perfect job and followed all the instructions. In spite of this, the few who had problems may very well have influenced the results for the experimental group, probably in a negative direction.

The samples used in the experiment were drawn from the same population. The division was not completely at random, but with the method used there are probably no systematic differences between the groups. Consequently, the differences between the groups are effects of the program or have occurred by chance.

The choice of driving schools for participation in the experiment was, however, more problematic.

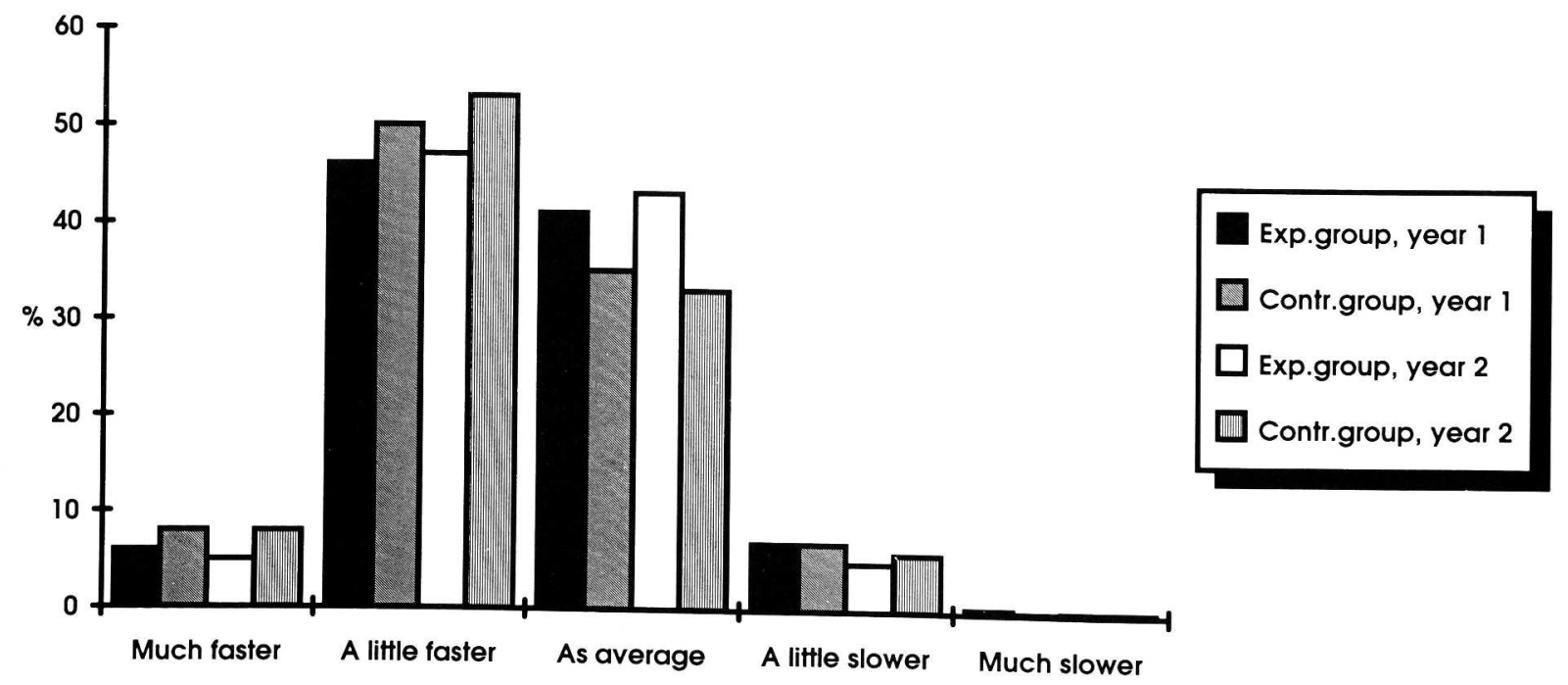

Fig. 5. Self-assessed driving speed compared to other car drivers, on rural roads. 
A model was chosen in which only interested driving schools were selected. In a way, this is an exception to the idea of reality. If the program is to be used generally in all schools, uninterested schools will also be included. If the model were to become mandatory, however, these uninterested schools would probably not put very much effort into making it work.

The consequence of this strategy is that the positive effects of the study may be overestimated.

As is often the case in road safety research as well as in epidemiological research in general, there is an important discussion to be held on the choice of effects to be studied, i.e. the choice of dependent variables. The main effects studied in this experiment are accident risks. Accident risk is no ambiguous term. It must be defined in terms of source and of the meaning of risk.

Normally two sources are available for accident reports on an individual basis, self-reported accidents and police records. The advantage of police records is that they are not biased by the experiment. There is a large proportion of dropout in the police register compared to the true number, but there is no reason to expect that there are different coverage rates in the control group and the experimental group. The problem is, however, that the number of police-reported accidents are few, about $1 \%-1.5 \%$ of drivers aged 18-19 years are reported.

Based on the learners' own reports, the number of accidents is much higher. The prevalence is $20 \%-40 \%$ of the drivers in the age group 18-19 years. The most important reason for the choice of self-reported accidents was that the size of the experiment had to be limited, since the project paid almost all the costs for the licence in the experimental group. If it had been possible to use much larger groups, the police records on accidents could have been used, but this was not possible.

One problem of using self-reported accidents is that the results may be influenced by the learners' tendency to report their own accidents. It is possible that there will be an underreporting tendency in the experimental group since they may be more eager to show how skilled they are. If so, the consequences would be an overestimation of the risk reducing effects.

Most of the data have been collected through questionnaires. Well-known techniques have been used and no specific problems have occurred in this work.

\section{Discussion of the results}

The main results are unexpected. A positive effect was found, but not before the second year after licensing. The hypothesis of risk reduction was accepted for year 2 but not for year 1 and not for the two years together. What could the explanation be? In general, the study itself offers no direct answers. There are, however, several hypothetical explanations, and some of these will be discussed below.

The first question is whether or not the assumptions of the potential risk reduction were correct in a theoretical sense. Were there any mistakes in the definition of the problems?

It would have been easier to accept this explanation of the results if there had been no differences between the groups. The results during the first year, showing a higher risk among those who were given the changes, make this much more difficult. Something in the measures must have acted in the opposite directions. Since the design does not make it possible to isolate the effects of each of the measures, there is no way of showing whether it is just one, two, or all of them that decrease or increase the risk.

Theoretically, there ought to be a risk-reducing effect from the three measures. Little research has been published on the visual search patterns of novice drivers. In a recent experiment by Miltenburg and Kuiken (1990) some comparisons were made on visual search strategies between drivers with different levels of experience. They failed to confirm the findings of Mourant and Rockwell (1972) and their own hypotheses of a relation between experience and search strategies. It is, however, impossible to interpret their findings on fixating close in front of the car for novice drivers compared to experienced drivers. Even if the hypothesis of different search strategies cannot be confirmed, it is not very probable that the method of "commentary driving" works against the idea of improved search strategies.

It is well documented that young drivers overestimate their own skill (Moe 1986, Matthews and Moran 1986; McGormick, Walkey and Green 1986). The problem of private education is, however, not sufficiently documented. In some recent studies, dated after the start of this experiment, no differences are shown between systems with and without mandatory driving schools. (Potvin et al. 1988; Levy 1988; 1990; see Gregersen 1992b for an overview.)

The second explanation deals with the implementation process. There was indications in the results from the process evaluation that problems existed. These problems, however, must be regarded as relatively small, since the majority was decidedly positive to the changes. If this explanation is valid, there ought to be a zero effect instead of a negative 
effect the first year and a positive etfect the second year.

A third possible interpretation has to do with the problem of the demands upon young drivers' cognitive capacity. Since they have to make conscious decisions for every move and every action they take, their capacity will sometimes be overloaded. In these situations, a driver cannot take everything into consideration and thus has to make priorities. If an inexperienced driver makes the wrong priorities, he may miss important information and increase his risk.

It is probable that the reduction of the demands upon cognitive capacity wili take some time and that much behaviour must be changed from conscious to automatic, i.e. much of the technical maneuvering of the car, many of the traffic rules, etc. (Brown. Groeger and Biehl 1987).

The results of the experiment may be interpreted as showing that this cognitive overload works against the way in which the novice driver makes use of the improvements. Even if the education succeeds in making the learner understand the problems and risks of driving and makes him aware of how to drive in specific situations, it is not obvious that he will make use of this awareness. On the contrary. it is possible that these aspects will hecome additional demands to take into account in difficult situations, which may confuse the driver even more and contribute to an even higher risk level. It is not until after the first period of driving that capacity is released, making it possible to make use of the experience of commentary driving, increased risk consciousness, etc.

If this interpretation is correct. the changes in the experimental group may have a potentially riskreducing effect, but this effect is counteracted by the problem of cognitive capacity. The learners atecept the messages, but cannot fully make use of them until later. This explains why a risk-reducing effect is seen during the second year. since the period of the highest demands on capacity has passed. When more cognitive capacity is freed, the driver can make use of all the experience and conclusions drawn from the improved education.

One conclusion from such an interpretation is that it is very difficult to find ways of improving the safety of novice drivers. This aspect always has to be taken into consideration. Possibly this is one of the explanations why there are still such high risks among young drivers all over the world. Many measures have been implemented and evaluated, but there are very few that have proved to reduce accident risks.

This also supports the ideas behind the French and the recently introduced Swedish system of driver education. In both countries the age limit for practicing has been lowered to 16 years. Though it has not been scientifically evaluated, the French system is claimed to have reduced accident risk among young drivers to a very low level. The basic idea is to gain experience during a two-year period of practice before receiving the licence and being allowed to drive unsupervised. During this time the driver will pass the first period of cognitive overload and gain capacity for focusing on more relevant factors in traffic, such as cooperating with other road users, predicting courses of events, moving the focus of scanning from near the car to a broader view of the traffic environment, etc.

It would have been interesting to see the effects of each component in the change package of our experiment. This would have given us a base upon which a deeper discussion could have been held. This is, however, impossible since we have only one experimental group exposed to all the changes. It would also have been interesting to have data on accident risk continually during the two years. With such data, it would have been possible to see if the change from year one to year two is a steady trend or not, or if there is some specific breakpoint.

Special training tasks were used with the purpose of reducing overestimation of skill among the learners. We do see some results in this direction, but the differences between the groups are few and very small.

One component of driving style is speed. Most of the learners in both groups report that they drive faster than the average on rural roads. During the second year, the control group reported higher speeds compared to the experimental group. The reason that those in the control group drive a little faster may be that they did not receive this insightcreating part of the education, and that the experimental group. which did receive it, lacked the capacity to make use of it until year 2. They were too oceupied with all the details of driving.

To a small extent, this is also supported by the results showing that the experimental group feels a little less clever than the control group immediately after licensing.

\section{CONCLUSIONS}

One conclusion is that the measures used in this experiment have some kind of influence upon the accident risk of the novice drivers. However, no risk reducing effects were achieved until the second year. This means that if the effects are real and 
not due to chance, the improvements need time to become apparent.

If more had been known about what happened during the third and the fourth year, it would have been possible to state whether this was the beginning of a trend, showing that the experimental group wins in the long run. With the existing data, there is no way of knowing, which leads to the overall conclusion that there was no risk reduction during the first two-year period as a whole, during the most problematic period for the novice drivers.

One conclusion is also that the experimental group, in line with our expectations, has achieved more positive results in aspects other than accident risk, i.e. lower speed and lower estimation of their own skills. This does not show up in reduced accident risk until the second year. As discussed above, the reason may be that learners, due to cognitive overload, need at least one year to make use of the improvements. If that is the case, the experiment did have some benefits, even if the changes did not succeed in reducing the highest initial overrisk among the novice drivers.

If this is true, one might suggest a driver education that makes it possible to gain enough experience to handle the cognitive overload. One way of dealing with this is to lower the age limit for driving practice, thus making it possible to practice for a long time before gaining a licence. This system has been introduced in Sweden, but the evaluation has just started and no results are yet available. One of the main points of this idea is that the driver has passed the period of cognitive overload when he gains his licence and starts to drive on his own.

In continued research, the complex and unexpected results from this study show a need for theoretical development and deeper understanding of novice drivers, the complexity of their problems, their motives for driving, their behaviour and the role of the cognitive load, as well as a deeper understanding of the process and effects of educational measures.

Acknowledgements-This research was supported by grants from the Swedish Road Safety Office (TSV), the Swedish Transport Research Board (TFB), the Swedish Association of Driving Schools (STR), the Road Safety Committee of the Swedish Insurance Industry (FSAB), and the Swedish Road and Transport Research Institute (VTI).

\section{REFERENCES}

Brown, I. D.; Goreger, J. A.; Biehl, B. Is driver training contributing enough towards road safety? In: Rothen- gatter, J. A.; de Bruin, R. A., editors. Road users and traffic safety. Assen, The Netherlands: Van Gorcum; 1987.

Evans, L.; Wasielewsky, P. Risky driving related to driver and vehicle characteristics. Accid. Anal. Prev. $15: 121-136 ; 1983$.

Evans, L.; Wasielewsky, P. O.; von Buseck, C. R. Compulsory seat belt usage and driver risk taking behaviour. Human Factors. 24:41-48; 1982.

Finn, P.; Bragg, B. W. E. Perception of the risk of an accident by young and older drivers. Accid. Anal. Prev. 18:289-298; 1986.

Gregersen, N. P. Integrated driver education: An experiment with structured cooperation between driving schools and private teachers (in Swedish). VTI Rapport 376. Linköping: Swedish Road and Transport Research Institute; 1992a.

Gregersen, N. P. Young drivers-Strategies to improve their traffic safety (in Swedish). VTI Rapport 358. Linköping: Swedish Road and Transport Research Institute; $1992 b$.

Levy, D. T. The effects of driving age, driver education, and curfew laws on traffic fatalities of 15-17 year olds. Risk Analysis 8:569-574; 1988.

Levy, D. T. Youth and traffic safety: The effect of driving age, experience, and education. Accid. Anal. Prev. $22: 237-334 ; 1990$.

Marek, J.; Sten, T. Traffic environment and the driver. Driver behaviour and training in international perspective. Springfield, IL: Charles C. Thomas, Publisher; 1977.

Matthews, M. L.; Moran, A. R. Age differences in male drivers' perception of accident risk: The role of perceived driving ability. Accid. Anal. Pre. 18:299-314; 1986.

McGormick, I. A.; Walkey, F. H.; Green, D. E. Comparative perceptions of driver ability-a confirmation and expansion. Accid. Ana. Prev. 18:205-208; 1986.

Miltenburg, P. G. M.; Kuiken, M. J. The effect of driving on visual search strategies: Results of a laboratory experiment. Report VK-90-24. Haren: Rijksuniversiteit Groningen; 1990.

Moe, D. Young drivers. Relation between perceived and real ability (in Norwegian). TFD Report 1984:5. Stockholm: Swedish Transport Research Board; 1984.

Mourant, R. R.; Rockwell, T. H. Strategies of visual search by novice and experienced drivers. Human Factors $14: 325-335 ; 1972$.

Potvin, L.; Champagne, F.; Laberge-Nadeau, C. Mandatory driver training and road safety: The Quebec experience. Am. J. Public Health 78:1206-1209; 1988.

Spolander, K. Accident risks of drivers. A model tested on mean and women (in Swedish). VTI Rapport 268. Linköping: Swedish Road and Transport Research Instiitute; 1983.

Spolander, K.: Rumar, K.; Lindkvist, F.; Lundgren, E. Safer beginner drivers. Suggestions for improved driver instruction (in Swedish). VTI Meddelande 404. Linköping: Swedish Road and Transport Research Institute; 1984.

Spolander, K. Men and women behind the wheel (in Swedish). Stockholm: Statistiska Centralbyrån (SCB); 1992. 


Forskar för ett liv i rörelse.

Research for an active community.

Statens väg- och transportforskningsinstitut har kompetens och laboratorier för kvalificerade forskningsuppdrag inom transporter och samhällsekonomi, trafiksäkerhet, fordon, miljö samt för byggande, drift och underhåll av vägar och järnvägar.

The Swedish Road and Transport Research Institute has laboratories and know-how for advanced research commissions in transport and welfare economics, road safety, vehicles and the environment. It also has research capabilities for the construction, operation and maintenance of roads and railways.

Telex 50125 VTISGI S 